\title{
Danish Exceptionalism: Explaining the Unique Increase in Social Trust over the Past 30 Years
}

\author{
Kim Mannemar Sønderskov \& Peter Thisted Dinesen *
}

[Preprint version, final version is forthcoming in European Sociological Review]

\begin{abstract}
Given the positive societal consequences of social trust and the exceptional high levels of trust found in the Nordic countries there is a growing interest in the background for Nordic trust exceptionalism. Reflecting the debate about the roots of trust, the question is whether this exceptionalism has been a permanent feature of these societies, i.e. an enduring cultural trait, or primarily been shaped by more contemporaneous experiential forces. This paper examines the roots of the present Nordic trust exceptionalism by means of analyzing the development of trust in Denmark over the last three decades. The analysis shows that trust in Denmark has increased remarkably from 1979 to 2009 thus documenting that the very high levels of trust found today are a relatively new phenomenon. This result contradicts the cultural perspective and instead vindicates the experiential perspective on trust. Subsequent analyses based on longitudinal data at the aggregate level as well as individual-level cross-sectional and panel data indicate that the increase in trust in Denmark can be attributed to generational replacement, increasing levels of education, improved quality of state institutions, and a concomitant increase in citizens' trust in these institutions.
\end{abstract}

\section{Keywords}

Keywords: social trust, institutional trust, institutional quality, education, panel data, Denmark

\footnotetext{
* The author listing purely reflects reversed alphabetical order of the last names as the authors contributed equally to the article.
} 


\section{Introduction}

Social trust is the belief that most people with whom one could potentially interact will behave in a trustworthy manner. A person's level of social trust thus reflects her standard estimate of the trustworthiness of the generalized, anonymous other (Coleman, 1990: 104; Robinson \& Jackson, 2001). ${ }^{1}$ Social trust is an important resource in modern societies, where citizens constantly interact with anonymous others whom they have no specific knowledge about. In many everyday interactions, e.g., shopping or driving in traffic, as well as more abstract and complex situations such as forming attitudes about political issues or deciding whether to pay taxes, citizens' behavior depend on their expectations about the behavior of other citizens. In such situations involving anonymous others, social trust serves as an important heuristic for behavior with significant positive consequences for society as a whole (Stolle, 2001; Sønderskov, 2008). This is supported empirically in a number of studies, which show that individuals with higher levels of trust contribute more to the provision of public goods through, e.g., tax paying, pro-environmental behavior, volunteering, and immunization (Gächter et al., 2004; Rönnerstrand, 2013; Scholz \& Lubell, 1998; Sønderskov, 2011a; Uslaner, 2002). Thus, there is little doubt that social trust is valuable resource for modern societies.

Because of its positive societal consequences, it is important to understand why some countries are characterized by high levels of social trust and others are not. In this regard, the Nordic countries Denmark, Sweden, Norway, Finland and Iceland - have attracted massive attention because they are outliers placed at the very top of the trust distribution ${ }^{2}$ (see, e.g., Bjørnskov, 2006, 2008) leading scholars to speak of “Nordic exceptionalism” (Delhey \& Newton, 2005). This naturally begs the question about the roots of this exceptionalism and, ultimately, whether other countries can learn from the Nordic countries with regard to building up trust. On a theoretical level this taps into a central debate about whether social trust is a long-standing cultural trait (Putnam, 1993; Uslaner, 2002), or a more manipulable characteristic that can be generated in the shorter term by contemporary experiences (Dinesen, 2012b; 2013; Glanville \& Paxton, 2007). In this regard, the Nordic countries are often seen as hallmarks of the cultural account because they share a number of deep historical structures known to correlate positively with trust, e.g. Protestantism and low ethnic diversity (Delhey \& Newton, 2005). On account of its historical correlates, the current elevated levels of trust are taken as an indication that high trust is a permanent feature of the Nordic culture. However, to show that the Nordic trust exceptionalism is indeed culturally founded, a much more direct test is to look at trust levels over time. If the present high levels of trust are stable back in 
time, this is a strong indication of a long-standing Nordic trust culture and thus the cultural account of the roots of trust. In contrast, if trust changes over time, it substantiates theories emphasizing how contemporary experiences influence trust, in turn leading to the questions of what these factors may be.

This paper examines the roots of present Nordic exceptionalism by means of analyzing the development of trust in Denmark - one of the global high-scorers in trust (Bjørnskov, 2006; 2008) over the last three decades. Using aggregate data our analysis shows that trust in Denmark has increased remarkably from 1979 to 2009 thus documenting that the very high levels of trust found today are a relatively new phenomenon. In theoretical terms, this result contradicts the cultural perspective and instead vindicates the experiential perspective on trust. Subsequently, we scrutinize a number of plausible experiential explanations for the increase in trust based on a longitudinal analysis at the aggregate level as well as individual-level cross-sectional and panel data. These analyses indicate that the increase in trust in Denmark can be attributed to generational replacement, increasing levels of education, improved quality of state institutions, and a concomitant increase in citizens' trust in these institutions.

\section{Explanations of social trust: Cultural and experiential perspectives}

As just noted, a central distinction within theories of the roots of trust is that between cultural and experiential explanations. The cultural perspective emphasizes how trust is passed on from parents to children through early life socialization (Uslaner, 2002; 2008) ${ }^{3}$ with little subsequent role for experiential alteration. As a consequence, the cultural perspective predicts levels of trust to be highly stable over the individuals' life course and over generations and therefore also at the society level. Illustrative of the cultural perspective, Uslaner (2008) shows that the level of trust of immigrants in the USA tends to reflect that of their grandparents' country of origin (see also Rice \& Feldman, 1997 and Tabellini, 2008). According to this perspective, Danish (and Nordic) trust exceptionalism, should thus be explained by a trust culture set in motion by forces dating back very far in time. In this regard, Svendsen \& Svendsen (2004) argue that the Danish co-operative movement, which arose among peasants in the late $19^{\text {th }}$ century, was built on a micro-foundation of trust and social capital among neighboring farmers, and that the movement further expanded the stock of society-level social capital, which in turn strongly influenced the later political and institutional development in Denmark with positive consequences for social trust. 
In contrast to the cultural explanation, the experiential explanation emphasizes the susceptibility of trust to various experiences. Such experiences are typically perceived broadly and thus encompass both more direct personal experiences (e.g. with other people in various settings), but also collective experiences influencing all individuals in a society (e.g. income inequality or wide-spread corruption) (Uslaner, 2002). The essence of the experiential perspective is that trust is malleable and thus probably not temporally stable. This perspective has also been substantiated by studies of immigrants in Western Europe, showing that destination country environments conducive to trust exercise a marked impact on immigrants' trust (Dinesen, 2012a, 2012b, 2013; Nannestad et al., 2014). In experiential terms, Danish trust exceptionalism, and changes in trust over time, would then be explained by trust-promoting experiences. In this regard, level of education, ethnic and economic diversity and the quality of state institutions are often emphasized as important explanations (Bjørnskov, 2006; 2008; Brehm \& Rahn, 1997; Delhey \& Newton, 2003; 2005; Dinesen, 2013; Dinesen \& Sønderskov, 2012a; Nannestad et al., 2014; Rothstein \& Stolle, 2008; Rothstein \& Uslaner 2005).

Having sketched the two main perspectives on the roots of trust above, it should be clear that they yield different predictions about the temporal dynamics of trust. The cultural perspective predicts temporal stability regardless of environmental developments, whereas the experiential perspective predicts increasing/decreasing trust in the face of major societal changes. Below we examine the leverage of the two perspectives in explaining Danish trust exceptionalism.

\section{Testing the cultural and the experiential perspective on trust in Denmark over time}

A straightforward test of the two perspectives on trust is to examine aggregate levels of trust over time. Using data from Denmark we are thus able to understand whether the Danish trust exceptionalism has been a stable cultural feature or instead appear to be a more recent phenomenon. Fortunately, Danish surveys holding a standard measure of social trust exist all the way back to 1979, thus providing a reasonably long time series to examine the dynamics of trust. Table 1 plots the estimated share of the Danish population responding that "most people can be trusted" to the classical dichotomous question "Generally speaking, would you say that most people can be trusted or that you cannot be careful when dealing with others?”. ${ }^{4}$ In order to contrast the Danish experience, we have also plotted data for a number of other countries, e.g. two other Nordic trust high-scorers, Norway and Sweden, and the US, which is known for its historical drop in trust (Clark \& Eisenstein, 2013; Putnam, 1995; 2000; Robinson \& Jackson, 2001; Uslaner, 2002). ${ }^{5}$ 
Figure 1: The development of social trust in selected countries

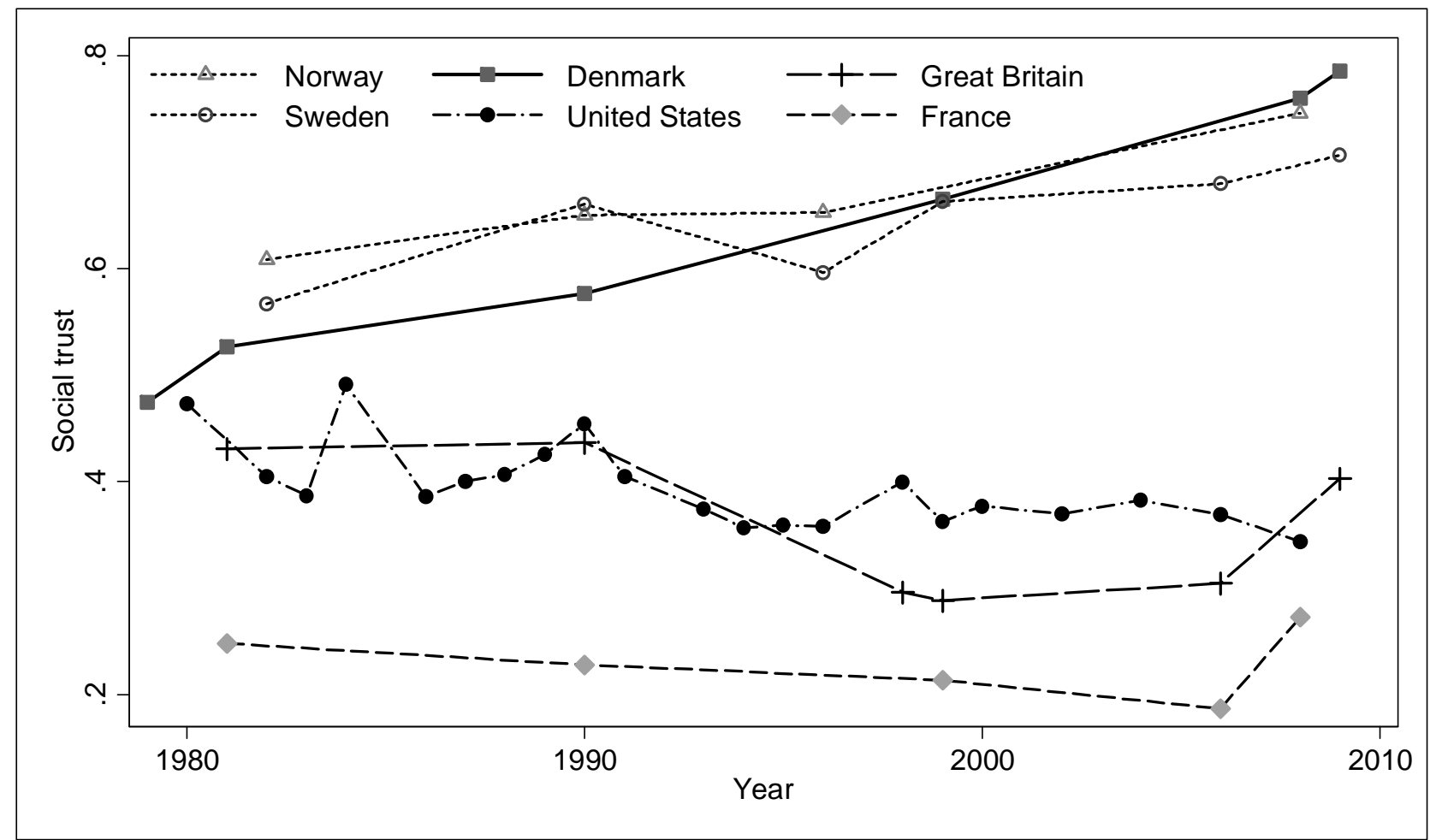

Notes: The level of trust is the share of the population answering that "most people can be trusted" to the question, "Generally speaking, do you that think most people can be trusted or that you cannot be too careful in dealing with others” after removing “Don’t know” responses. Sources: World Values Survey 1981-2008 (WWS 2009) (data for Norway, Sweden, US, GB, France); European Values Study 1981-2008 (EVS 2011) (all countries); General Social Survey 1972-2010 (GSS 2011) (US); Politiske værdier i Danmark 1979 (Danish Data Archive 1981) (Denmark); Social ulighed i Danmark 2009 (Danish Data Archive 2011) (Denmark). When more than one survey contains data for the same country in the same year, we report the pooled share expressing trust.

Figure 1 tells an unequivocally clear story with regard to the development of trust in Denmark over the past 30 years. In 1979, 47\% expressed that “most people can be trusted”, whereas this share had increased to $79 \%$ in 2009 , thus leading to a remarkable increase in trust of about a third of the possible range over the 30 year period. This huge monotonic increase in trust strongly suggests that trust is not temporally stable and that the very high levels of trust presently found in Denmark are a relatively new phenomenon. This in turn implies that Danish trust exceptionalism is primarily rooted in more recent experiences rather than a cultural heritage. The comparative picture also underlines that Danish levels of trust have in fact only turned exceptional in more recent years. In 1979, Danish levels of trust were on a par with the level in the US in 1980, and going even further back in time, 58\% of Americans trusted most people in 1960 (Putnam, 1995), a substantially higher share than the $47 \%$ in Denmark in 1979. Similarly, the level of trust in Denmark was only slightly higher than that in Great Britain in 1981, and in the beginning of the eighties Denmark was lagging 
somewhat behind its Scandinavian counterparts. That said, Danish levels of trust in the late seventies was fairly high by both that time's as well as present day standards (Delhey \& Newton, 2005; Bjørnskov, 2008), so we cannot rule out whether this baseline has cultural roots. However, the emergence of Danish trust exceptionalism from 1979 onwards clearly indicates the dominance of experiential forces in explaining the more recent development. With this in mind, we will now turn to the question of which experiential factors underlies this development.

\section{Explanations of the Danish increase in trust: cohort and period explanations}

A central distinction within the experiential perspective relates to whether experiences at certain points in time have different effects on trust. One line of thought emphasizes how trust is continuously formed throughout life (Dinesen, 2012b, 2013), while another view argues that experiences during childhood and adolescence often leave a lasting mark on trust and other attitudes (Robinson \& Jackson, 2001). The latter perspective thus shares the idea of the importance of early life factors in shaping subsequent levels of trust with the cultural perspective (Uslaner, 2002, ch. 4), but does not preclude the importance of experiences later in life, that is, early life experiences can be seen as a baseline from which the influence of subsequent experiences depart. The distinction between the two experiential perspectives parallels the discussion within the literature on attitude formation regarding the "impressionable years" hypothesis versus the "lifelong openness to experience” hypothesis (Sears \& Levy, 2003). Similarly, it also relates to the literature on value change distinguishing between cohort and period explanations of change (Glenn, 2005; Robinson \& Jackson, 2001). ${ }^{6}$ Cohort explanations focus on how people born around the same time are subject to the same environment and circumstances (and thus have common experiences), and therefore tend to have similar values over their life courses. While the common experiences shaping values may in principle occur throughout life, it is often assumed - in accordance with the "impressionable years" hypothesis - that experiences in late adolescence and early adulthood play an especially important role in shaping values. Given its focus on value homogeneity within cohorts due to common experiences, the cohort explanation explains value change by older generations with one set of values being replaced by younger generations with another set of values. The cohort explanation of trust has received considerable support in Robert Putnam's analysis of social capital in the USA, in which he finds that the main cause of decline in indicators of social capital (including social trust) is generational replacement of “the long civic generation” born before 1930 by younger cohorts 
(Putnam, 2000: Ch. 8, 14-15; see also Clark \& Eisenstein, 2013; Robinson \& Jackson, 2001; Schwadel \& Stout, 2012).

Whereas cohort explanations emphasize the importance of early-life environment, period explanations stress how societal factors and specific events in a given period of time affect everyone equally independent of cohort. Hence, general societal changes such as those regarding economic redistribution, ethnic composition, and institutional set-up are expected to influence the values of all citizens in a similar manner. In the following we evaluate these explanations using aggregate data over time from Denmark, and subsequently test the most promising explanations more rigorously using individual-level data.

Figure 2: The development of social trust for $20^{\text {th }}$ century Danish cohorts

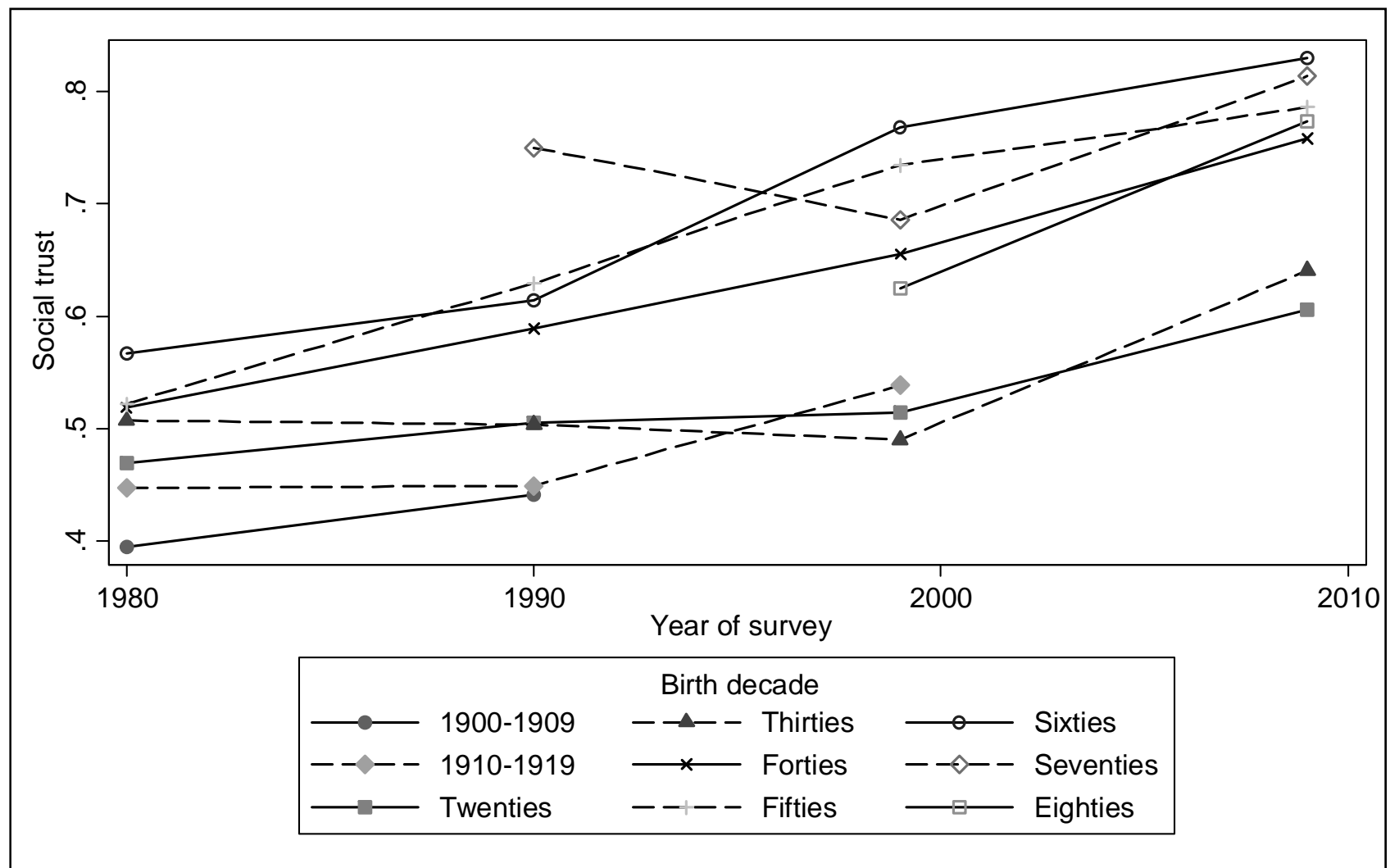

Notes: Social trust is measured as in Figure 1. The data point in 1980 is the pooled share expressing trust in two surveys (1979 and 1981). The 2009 data point is the pooled share expressing trust in surveys from 2008 and 2009. Data points based on less than 20 respondents are omitted. Sources: European Values Study 1981-2008 (EVS 2011); Politiske værdier i Danmark 1979 (Danish Data Archive 1981) Social ulighed i Danmark 2009 (Danish Data Archive 2011).

\section{Cohort explanations and changes in trust}

In order to assess the cohort explanation of the increase in trust in Denmark over the past 30 years, we examine the level of trust (measured between 1979 and 2009) for birth cohorts from the first nine decades of the $20^{\text {th }}$ century in Figure 2. The trends in trust among the different cohorts provide 
partial evidence in favor of the cohort explanation as older cohorts (i.e., those born in the beginning of the $20^{\text {th }}$ century) display lower levels of social trust than cohorts born later in the century. In 1980, 30 percent of the population was born before 1930, while these cohorts' share of the population had dropped to 10 percent in 2005 . $^{7}$ Hence, a part of the increase in social trust in Denmark seems to be due to the replacement of older, less trustful cohorts with younger, more trustful cohorts.

Having identified a cohort effect begs the question of what explains this difference in trust between younger and older generations. In this regard, rising levels of education is a prominent candidate as higher levels of education have systematically been shown to be associated with higher levels of trust at the individual level (Brehm \& Rahn, 1997; Delhey \& Newton, 2003; Putnam, 1995; Uslaner, 2002: Ch. 5). Given the rising levels of education in Denmark over time (see Figure 3 below), it seems plausible that the replacement of older cohorts with younger, and better educated, cohorts can explain some of the observed cohort effect in Figure 2. Consequently, we examine education as an explanation for the cohort effect in trust in the subsequent analyses.

While Figure 2 documents a cohort effect, it also testifies to generational replacement not being the only explanation of the rising levels of trust in Denmark as trust rises almost in parallel for all cohorts over the period of time examined. This indicates that social trust is not a value set in stone from early on in life, which is immune to subsequent experiences. Instead, the parallel increase in trust over time across cohorts indicates that general societal changes - and hence period explanations - can account for at least part of this development. This is the question we turn to next.

\section{Period explanations and changes in trust}

To explain the rising levels of trust, we examine three of the main societal factors (and thus period explanations) identified in the literature: economic equality, ethnic homogeneity, and institutional quality.

A number of studies have shown that citizens in more economically equal societies also tend to have higher levels of trust. This is explained by a stronger sense of community among citizens in these societies and by low levels of inequality reducing the potential gains from engaging in untrustworthy behavior (Bjørnskov, 2006; 2008; Rothstein \& Uslaner, 2005; Uslaner, 2002). Ethnic homogeneity has also been identified as a potential explanation of social trust. Lower degrees of ethnic conflict, and greater predictability of the actions of people of similar ethnic backgrounds are some of the factors suggested to lead to higher levels of trust in ethnically homogeneous societies 
(Delhey \& Newton, 2005; Dinesen \& Sønderskov, 2012a; Knack \& Keefer, 1997). Finally, quality of government in terms of fair and efficient state institutions is a third societal explanation of social trust. According to this view, institutional quality lays the foundation for social trust by sanctioning treacherous behavior and thus reducing incentives for behaving in an untrustworthy manner, and by securing equal treatment of citizens and hence reduce suspicion of others. Moreover, when the representative of fair institutions - either bureaucrats or publicly elected politicians - behave in an incorrupt manner, they send the signal that this type of behavior is not widespread in the population and, hence, that most people can be trusted (Rothstein \& Stolle, 2008).

To get a first hint about whether rising levels of education can explain the cohort effect observed in Figure 2, and whether income inequality, ethnic heterogeneity, and institutional quality appear to be plausible period explanations of increasing trust in Denmark since 1979, we have illustrated the development in these factors in Figure 3.

Panel A in Figure 3 shows the development in the level of education in Denmark and whether looking at average schooling or the share of people with education above primary school, there has been a steady increase over the period examined. Hence, it seems plausible that at least some of the cohort effect found for social trust can be explained by rising levels of education, with older cohorts, who are both less well educated and less trustful, gradually being replaced by younger cohorts, who are better educated and more trustful.

Panel B shows that economic inequality has generally increased over the period examined, which points to a negative relationship between trust and economic equality. This is surprising as earlier studies generally show a negative relationship between social trust and economic inequality (Bjørnskov, 2006; 2008; Uslaner, 2002; Rothstein \& Uslaner, 2005, but see Dinesen \& Sønderskov, 2013 and Fairbrother \& Martin, 2013 for recent within-country studies showing no effect of inequality). Given that this relationship is well established in the literature, the negative correlation between trust and equality should probably not be interpreted causally. It seems more reasonable to conclude that social trust either is unrelated to inequality or that it has increased despite of - and not because of - economic inequality. For this reason, we will not pursue this explanation in more detail in the present analysis. 
Figure 3: The development of educational attainment, economic inequality, ethnic diversity, and institutional quality/trust in Denmark

Notes: Average years of schooling is from Barro \& Lee (2010) (variable name: yr_sch); Share of the population with at

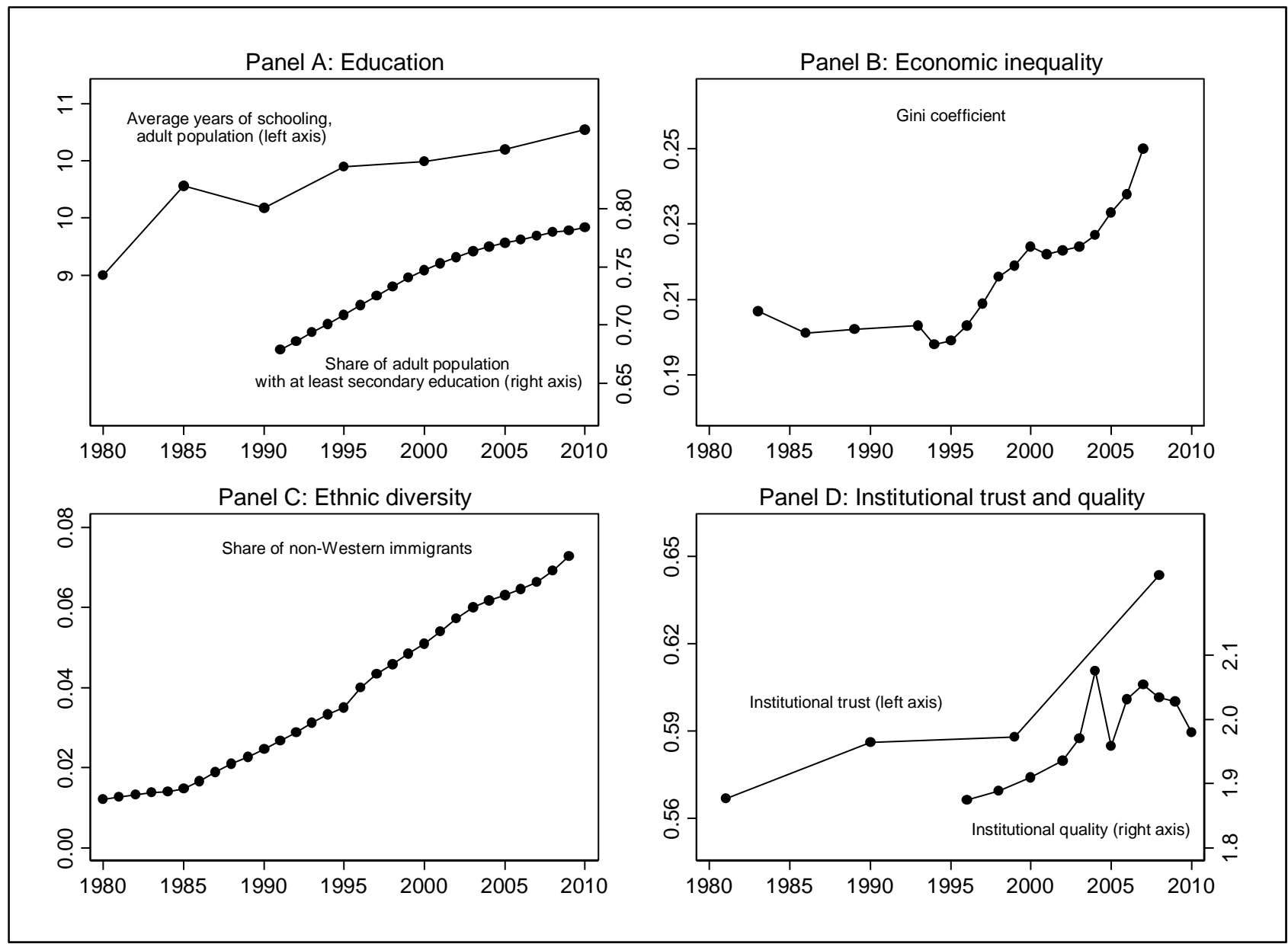

least secondary education is calculated based on data from Statistics Denmark (accounts: HFU1, KRHFU1, BEF5); The Gini-coefficient is from Finansministeriet (2010); Share of non-Western Immigrants is from Statistics Denmark (accounts: BEF3, KRBEF3). Institutional quality is from The Worldwide Governance Indicators project (Kaufmann et al., 2011) and is calculated as the average of the following variables: Voice and Accountability, Government Effectiveness, Regulatory Quality, Rule of Law and Control of Corruption. Institutional trust is the average level of trust in a number of state institutions in the adult population on a scale from 0 to 1 , where 1 signifies high trust (see the section "Measures" in the text for more details).

Panel C shows a pattern of increasing ethnic diversity over the period examined, which, on the face of it, suggests an unexpected positive relationship between ethnic heterogeneity and trust. However, as for the unexpected positive correlation between economic inequality and trust, this relationship should most likely not be given a causal interpretation. In fact, Dinesen \& Sønderskov (2012a) show that increased diversity in Danish municipalities (examined over the same period as in this paper) has a negative impact on trust, which leads them to argue that trust might have increased even further at the national level had it not been for increased ethnic diversity (see also Dinesen \& 
Sønderskov, 2013). Hence, we will not examine the role of ethnic homogeneity in explaining the rise in trust in more detail in the following.

The last panel in Figure 3 maps the development in institutional quality in Denmark and trust in institutions among Danish citizens. Apparently, institutional quality has generally improved in the period for which data exists although the increase is waning in the last part of the period. ${ }^{8}$ Moreover, the improvements seemingly manifest themselves in citizens' trust in state institutions, although with a lag. Contrary to the development in economic inequality and ethnic heterogeneity, the improved institutional quality corresponds to our theoretical expectation. Hence, improved quality of state institutions and a subsequent increase in institutional trust seem like a plausible explanation for the increase in social trust based on Figure 3.

Summing up, the patterns in Figures 2 and 3 suggest that the marked increase in social trust in Denmark can be explained by two factors: first, generational replacement in terms of higher educated, more trustful cohorts replacing older, less well-educated cohorts and, second, improved institutional quality and subsequent increases in institutional trust. Although both explanations square well with the literature, and as such appear to be plausible explanations for the rising levels of trust, we have so far only presented aggregate, bivariate evidence for the two explanations. In order to test these explanations more rigorously, we propose four hypotheses, which we test by means of multivariate analysis using individual-level data.

\section{Individual-level analysis}

If the increase in social trust is due to generational replacement, the older cohorts, whose share of the population is waning, should have lower levels of trust than younger cohorts. We test this hypothesis using data from 2008. At this point in time, it is primarily cohorts born before 1930 that are being replaced, and we therefore hypothesize:

$H_{1}$ : Cohorts born before 1930 have lower levels of social trust than younger cohorts.

If the increase in social trust can be attributed to rising levels of education, we should see that the higher educated have higher levels of trust than the lower educated. Moreover, if the potential cohort effect is partly explained by older cohorts being lower educated than younger cohorts, we expect to find the differences between cohorts reduced when education is held constant in the model. Hence, we propose the following hypotheses:

$\mathrm{H}_{2}$ : Higher educated people have higher levels of social trust than lower educated people. $\mathrm{H}_{3}$ : The cohort effect is reduced when education is held constant. 
The importance of institutional quality is somewhat harder to test. Country-level measures of institutional quality coinciding with public opinion surveys on social trust are too few to allow testing whether improvement in institutional quality is the cause of increased social trust over time. For that reason, we cannot assess whether the increased level of social trust in Denmark can be attributed to changes in national-level institutional quality. However, Wang \& Gordon (2011) report a cross-country relationship between institutional quality and institutional trust, which is an individual-level indicator of perceived institutional quality, and we therefore examine whether institutional trust affects social trust in the Danish case. If so, this would be an indication of the importance of the role of institutional quality in explaining the development in social trust. Hence, we hypothesize:

$\mathrm{H}_{4}$ : People with higher levels of trust in state institutions have higher levels of social trust than people with lower levels of institutional trust.

\section{Data}

In testing hypotheses $\mathrm{H}_{1}$ to $\mathrm{H}_{3}$, we utilize the Danish part of the European Value Survey from 2008 (EVS, 2011), which is a random sample of the adult population in Denmark. The survey was conducted by means of face-to-face interviews with a response rate of 51 percent. $\mathrm{H}_{4}$ is also tested with these cross-sectional data. However, some authors argue in favor of reverse causality and hence that social trust affects trust in institutions (or institutional quality) (Bjørnskov, 2006; Knack, 2002; Robbins, 2012; Uslaner, 2002: 158). Thus, a correlation between institutional trust and social trust cannot a priori be considered support for the institutional explanation of increased levels of social trust as using cross-sectional survey data to substantiate a causal relationship between two (attitudinal) variables is generally problematic. For that reason we also test $\mathrm{H}_{4}$ using panel data. We build on survey data from a panel of randomly sampled individuals who were interviewed in 1990, 1999, and 2008 in connection to the Danish part of the European Value Survey (Danish Data Archive, 2002; 2009). ${ }^{9}$ As in most panel surveys, a number of respondents dropped out of the survey between the waves, which means that the panel survey cannot be assumed to be representative of the original population in 1990. Despite this problem, the panel survey provides increased leverage for examining the causal relationship between the two types of trust at the individual level and thus strengthens the potential evidence in favor of the institutional explanation of the increase in social trust. 


\section{Specifications}

$\mathrm{H}_{1}$ regarding cohort effects is tested in Model I in Table 1, which include birth cohort as well as gender and place of birth. $\mathrm{H}_{2}$ and $\mathrm{H}_{3}$ regarding the mediating effect of education are tested by adding level of education in Model II. The first test of $\mathrm{H}_{4}$ is reported in Model III, in which institutional trust is added along with a number of additional control variables suggested in the literature (see, e.g., Uslaner, 2002). Specifically we include employment, income, life satisfaction, and self-efficacy, which are all potential mediators of the impact of birth cohort and education analyzed in Model II. Finally we also include associational involvement - a prominent explanation of social trust - although recent studies have made a case for reverse causality, i.e. that trusting individual self-select into voluntary organizations (e.g. Bekkers, 2012; Stolle, 2001; Sønderskov, 2011b). ${ }^{10}$

In Models IV-VII in Table 2, we examine if a correlation between institutional trust and social trust can be given a causal interpretation using the panel survey. Specifically, in Model IV, we examine whether institutional trust measured in the two first waves in 1990 and 1999 can explain social trust in 2008 when simultaneously controlling for social trust in 1990 and 1999. If institutional trust measured in the two earlier waves of the survey influences social trust in the last wave while controlling for previous levels of social trust, we take it as evidence in favor of a causal effect of institutional trust on social trust because previous levels of institutional trust predicts future levels of social trust net of previous levels of social trust. However, the analysis is restricted to a very limited sample because only 324 respondents chose to participate in all three waves of the panelsurvey (and to answer all relevant questions). In Model V, we therefore only include one lag by including respondents who participated in $1999\left(\mathrm{t}_{-}\right)$and $2008\left(\mathrm{t}_{0}\right)$ or, alternatively, respondents who did not participate in 2008 but in $1990\left(\mathrm{t}_{-1}\right)$ and $1999\left(\mathrm{t}_{0}\right)$. This allows us to test the relationship on a larger and more representative sample. The reverse relationship between the two forms of trust (i.e. with social trust as the dependent variable) is examined in Models VI and VII using the same logic applied in the model with institutional trust as the dependent variable. This serves to scrutinize whether causality runs in the other direction or both ways. Ideally, including the lagged dependent variable would serve to take into account the impact of all alternative factors influencing trust, but as a considerable time lag is present between the three measurements of the two types of trust, the viability of this strategy is somewhat questionable, and we therefore include the same control variables as in Model III (all measured in 2008) to avoid confounding of the relationship between the two types of trust by other extraneous factors. 


\section{Measures}

As previously, social trust is measured by the question, "Generally speaking, do you think that most people can be trusted or that you cannot be too careful in dealing with other people?” with the two response options, "Most people can be trusted" and "You cannot be too careful”, of which the first indicates social trust. Birth cohort is operationalized as the decade of birth, where respondents born before 1930 are collapsed in a single category to avoid having too few observations in the oldest cohorts. Education is measured in five categories: primary school, vocational education, shorter post-secondary education (1-2 years post high school), medium-long post-secondary education (3-4 years post high school), and academic education (more than 4 years post high school). Institutional trust is measured with an index of trust in four state institutions: the parliament, the judiciary, the police, and the public sector. Therefore, we construct an additive index based on trust in the four institutions. The constructed index ranges from 0 (low trust) to 1 (high trust) and indicates each respondent's average score on the four trust items. ${ }^{11}$ Details about the coding of the control variables as well as descriptive statistics for all variables are found in Table A in the supplementary material.

\section{Analysis}

Table 1 displays the results of the empirical test of hypotheses $\mathrm{H}_{1}$ to $\mathrm{H}_{3}$, which are tested using the cross-sectional survey from 2008. Since social trust is measured dichotomously, the models are estimated using logistic regression. Model I substantiates that generational differences between cohorts can explain part of the increase in trust in Denmark. People born before 1930 (the reference category) have significantly lower levels of trust than all other cohorts except for the cohort born in the 1930's. Moreover, it should be noted that the difference in trust between the oldest and the younger cohorts is probably underestimated given that a larger fraction of the oldest cohort has passed away in 2008. As social trust is positively correlated with indicators of health (see, e.g., Rostila, 2007), it seems likely that the individuals who live longer are generally the more trustful. 
Table 1: Causes of social trust, cross-sectional data

\begin{tabular}{|c|c|c|c|c|c|c|}
\hline \multirow{2}{*}{ 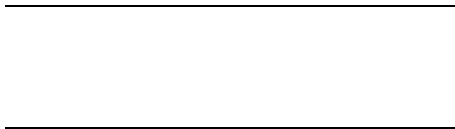 } & \multicolumn{2}{|c|}{ Model I } & \multicolumn{2}{|c|}{ Model II } & \multicolumn{2}{|c|}{ Model III } \\
\hline & Coef. & S.E. & Coef. & S.E. & Coef. & S.E. \\
\hline Birth cohort & \multicolumn{2}{|c|}{$* * *$} & \multicolumn{2}{|c|}{$* * *$} & & \\
\hline Before 1930 & \multicolumn{2}{|c|}{ Reference } & \multicolumn{2}{|c|}{ Reference } & \multicolumn{2}{|c|}{ Reference } \\
\hline 1930’s & 0.18 & 0.31 & 0.03 & 0.33 & 0.08 & 0.36 \\
\hline 1940’s & 0.58 & $0.30 *$ & 0.38 & 0.31 & 0.28 & 0.34 \\
\hline 1950’s & 0.80 & $0.30 * *$ & 0.43 & 0.32 & 0.23 & 0.37 \\
\hline 1960’s & 1.44 & $0.31^{* *}$ & 1.06 & $0.32 * *$ & 0.79 & $0.39 *$ \\
\hline 1970’s & 1.09 & $0.31^{* *}$ & 0.55 & 0.33 & 0.34 & 0.39 \\
\hline 1980’s & 0.77 & $0.32 *$ & 0.31 & 0.34 & 0.19 & 0.38 \\
\hline Gender (female) & 0.09 & 0.13 & -0.09 & 0.14 & -0.02 & 0.15 \\
\hline Place of birth (native) & 1.12 & $0.25^{* *}$ & 1.29 & $0.27 * *$ & 1.29 & $0.27 * *$ \\
\hline \multicolumn{3}{|l|}{ Education } & \multicolumn{2}{|c|}{$* * *$} & \multicolumn{2}{|c|}{$* * *$} \\
\hline \multicolumn{3}{|l|}{ Primary school } & \multicolumn{2}{|c|}{ Reference } & \multicolumn{2}{|c|}{ Reference } \\
\hline Vocational & & & 0.51 & $0.17 * *$ & 0.37 & $0.17^{*}$ \\
\hline Shorter post-secondary & & & 1.13 & $0.19 * *$ & 0.98 & $0.20 * *$ \\
\hline Medium-long post-secondary & & & 1.58 & $0.24^{* *}$ & 1.41 & $0.24^{* *}$ \\
\hline Academic & & & 2.29 & $0.35 * *$ & 2.05 & $0.38 * *$ \\
\hline Institutional trust & & & & & 2.03 & $0.48^{* *}$ \\
\hline Employed (yes) & & & & & 0.27 & 0.19 \\
\hline \multicolumn{7}{|l|}{ Relative household income } \\
\hline \multicolumn{3}{|l|}{$<25$. Percentile } & & & \multicolumn{2}{|c|}{ Reference } \\
\hline Inter quartile range & & & & & -0.01 & 0.19 \\
\hline >75. Percentile & & & & & 0.06 & 0.29 \\
\hline Not revealed & & & & & -0.25 & 0.19 \\
\hline Associational involvement & & & & & 0.42 & $0.15^{* *}$ \\
\hline Life satisfaction & & & & & 0.89 & $0.31 * *$ \\
\hline Self-efficacy & & & & & 0.63 & 0.37 \\
\hline Constant & -0.70 & 0.36 & -1.22 & $0.39 * *$ & -3.63 & $0.61^{* *}$ \\
\hline$\overline{\mathrm{N}}$ & \multicolumn{2}{|c|}{1,455} & \multicolumn{2}{|c|}{1,455} & \multicolumn{2}{|c|}{1,455} \\
\hline McFaddens $\mathrm{R}^{2}$ & \multicolumn{2}{|c|}{0.04} & \multicolumn{2}{|c|}{0.10} & \multicolumn{2}{|c|}{0.12} \\
\hline
\end{tabular}

Notes: *; **: $\mathrm{P}<0.05 ; 0.01$ (two-tailed tests). The joint significance of categorical variables is tested using an F-test, and the level of significance is indicated in the first row for each categorical variable. The table reports logit coefficients and robust standard errors.

Model II includes education and control variables that are expected to be causally prior to education. The results provide evidence in favor of $\mathrm{H}_{2}$, stating that higher education is associated 
with higher social trust. In order to have an idea about the magnitude of the impact, we predicted the average probability of trusting others at different levels of education, and this points to a strong effect. The average predicted probability of expressing trust for a respondent with primary school as highest education is 0.58 , while it is 0.93 if s/he had an academic education. ${ }^{12} \mathrm{H}_{3}$ is also partially supported in Table 1 as the differences in trust between the cohorts are reduced when education is introduced to the model, but they do not disappear entirely. This indicates that the cohort effect on trust is in part due to generational differences in the level of education.

A strong association between institutional trust and social trust is evident from Model III. Despite controlling for a large number of possible confounders, institutional trust has a significant impact on social trust, which supports $\mathrm{H}_{4}$. The average predicted probability of trusting others increases from 0.56 to 0.87 when comparing the lowest to the highest level of institutional trust. Hence, institutional trust has a marked impact on social trust, roughly corresponding to that of education (based on Model II).

However, an association is not enough to substantiate a causal impact of institutional trust on social trust as noted earlier, and to provide further support for the suggested interpretation of this correlation, we examine the causal relationship between the two types of trust in Table 2.

Models IV and VI in Table 2 show that both forms of trust measured in 2008 are markedly influenced by the same type of trust measured in 1999, and for institutional trust, trust in 2008 is even influenced by trust in 1990. In relation to the present research question, the interesting finding is that institutional trust in 1999 has a significant impact on social trust in 2008 despite controlling for social trust measured in 1999 and 1990 and a large number of control variables. Moreover, we do not find the reverse relationship, as there is no evidence for an effect of social trust measured in 1990 or 1999 on institutional trust in 2008. Similarly, in the models with only one time lag (Models $\mathrm{V}$ and VII), we also find only an effect of institutional trust on social trust and not the reverse relationship. This is evidence of institutional trust having a causal impact on social trust and not the other way around. Furthermore, to underline the importance of institutional trust in forming social trust, it should be noted that this is the only variable apart from lagged social trust and education that significantly influences social trust (at the 0.05-level) in Models IV-V. Even associational involvement, the previously prominent explanation of social trust, is insignificant and close to zero once previous levels of social trust are controlled for. This finding is consistent with the selfselection hypothesis, i.e. that social trusters are more likely to join voluntary associations (Stolle, 2001). 
Table 2: Causes of social trust and institutional trust, panel data

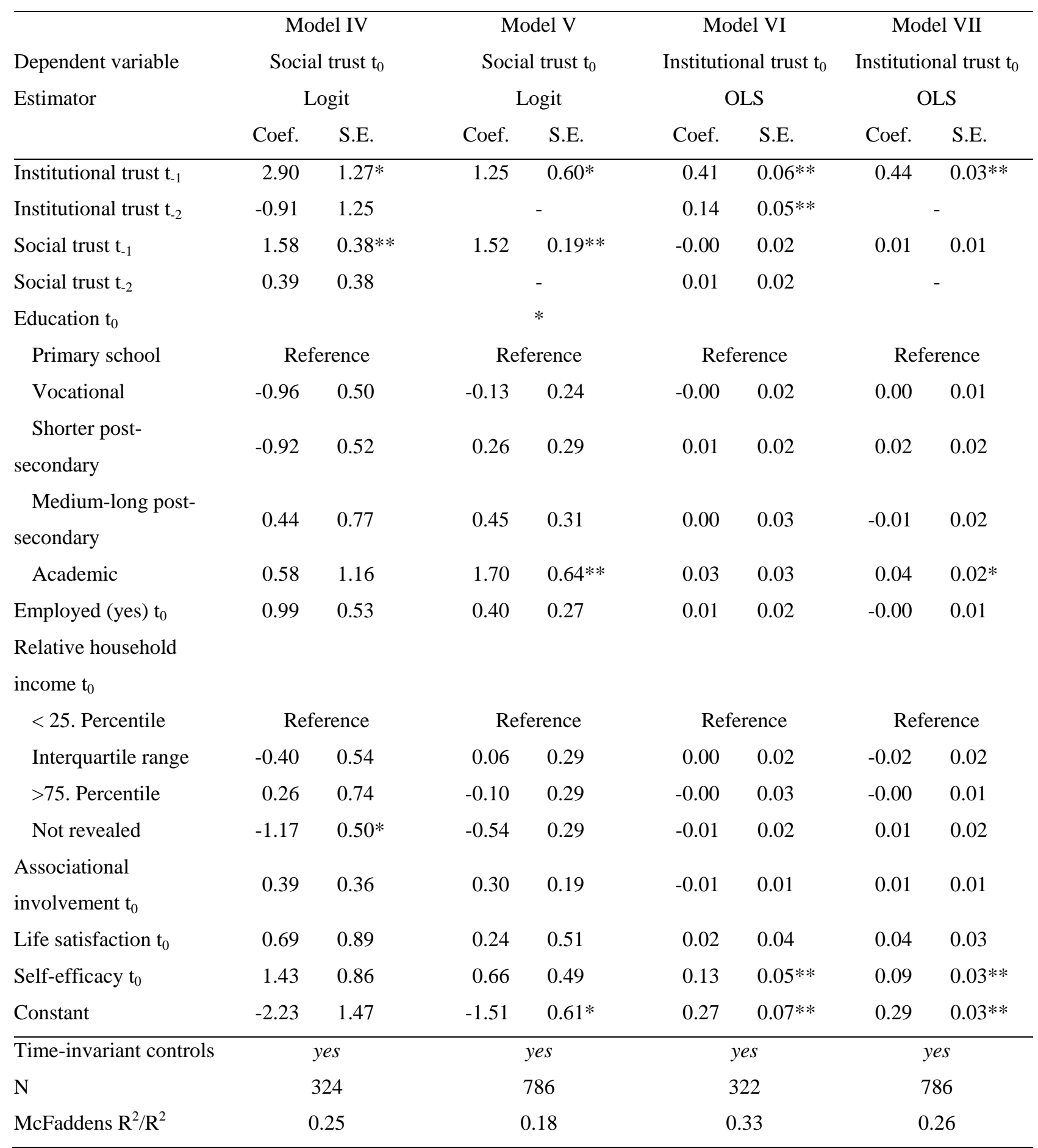

Notes: *; **: P < 0.05; 0.01 (two-tailed tests). The joint significance of categorical variables is tested using the F-test, and the level of significance is indicated in the first row for each categorical variable. The table reports coefficients and robust standard errors. $\mathrm{t}_{0}, \mathrm{t}_{1}$, and $\mathrm{t}_{-2}$ refer to 2008, 1999, 1990, respectively, in Models IV and VI. In Model V and VII, $t_{0}$ and $t_{-1}$ refer to either 2008 and 1999, or 1999 and 1990. Models IV-VII contain the same control variables as in Table 1 , but the coefficients for the time-invariant variables birth cohort, gender, and place of birth are not shown. 
Finally, a word on the insignificant effect of education on social trust in Model IV, which may be seen as a weakening of $\mathrm{H}_{2}$. The insignificance is likely to be caused by little individual-level variation in education over time. Since this is a sample of adults, the level of education does not change much over time for most respondents, which implies that most of the effect of education is probably captured by the lagged trust variable in Model IV.

In sum, the analyses generally support the four hypotheses put forward. Hence, our results indicate that the increasing levels of trust over the past 30 years are the result of generational replacement and concomitant rising levels of education as well as increasing levels of trust in institutions, which appear to reflect the quality of state institutions.

\section{Conclusion and discussion}

Evidence suggests that the level of social trust in Denmark is (among) the highest in the world today. Given that social trust is an important resource contributing to the provision of public goods and promoting cooperation, this paper has sought to understand the background for this exceptionalism and thus the factors that may work to increase trust more generally. We have examined two generic types of explanations for the high level of trust: cultural and experiential explanations. An analysis of the development in trust over the past 30 years showed that it Danish trust exceptionalism is a recent phenomenon as trust has increased dramatically in Denmark over the last 30 years. This clearly suggests that the deep historic factors embodied in the cultural perspective on trust cannot explain the elevated present-day level of trust in the Danish case. Instead our results suggest that the increasing levels of trust, and hence the current trust exceptionalism, can best be understood in experiential terms as a combination of cohort and period effects. More specifically, we find that generational replacement explains part of the increase in social trust as trust is significantly lower among older cohorts. Moreover, our analyses show that the differences in trust between cohorts can, to a considerable extent, be explained by differences in educational levels. Finally, we also found that (increased) institutional quality is the most powerful period effect explaining the increase in trust.

These results are good news for benevolent policy-makers and others who strive to grow social trust, as our results clearly indicate that social trust is indeed manipulable if not in the short term then at least in the medium term. If levels of social trust were mainly the product of forces set in motion centuries ago, this would leave reformers without tools to promote trust. Given the positive influence of education and institutional quality mediated through institutional trust our results 
suggest that promoting higher education and building up well-functioning state institutions can foster social trust. Importantly, the present analysis also provides rather strong evidence that causality actually runs from institutional trust to social trust and not the other way around. This suggests that fair and efficient state institutions promote social trust, and that improving the quality of state institutions probably is a viable strategy in order to uphold and potentially build up the valuable resource of social trust. This is a rather different strategy than a previously prominent receipt for promoting trust, namely that of furthering associational engagement, which, our results show only have a limited effects on social trust. In that sense, our results add to the growing pile of evidence suggesting that institutions rather than civic life are the main driver of social trust.

The increase in social trust among Danes is striking in a comparative perspective, but the results of the analysis of the causes of this development are also interesting when compared to within-country analyses from other countries. Most remarkably, the results reveal reverse consequences of generational replacement for social trust in Denmark and the US. The present analysis showed that the oldest cohorts are less trustful than the younger cohorts in Denmark. The opposite is found in the US, where cohorts born approximately before the end of World War II are more trustful than younger cohorts, which explains a large part of the much discussed drop in social trust in this country (Putnam, 1995; Robinson \& Jackson, 2001). Consequently, the level of trust among the cohorts born before 1945 appears to have been largely similar in the two countries, perhaps with a small lead to the US (Putnam, 1995: 675). This suggests that the divergent trends in trust between the two countries were founded among the cohorts born after the war. This naturally leads to the question about which differences in the post-war cohorts' environments in the two countries that may account for these divergent trends. Given that the two countries obviously differ in a great number of ways, one can only speculate about this explanation. On the face of it, education would not be able to explain this divergence as education has generally been increasing in the second part of the $20^{\text {th }}$ century in both countries. However, it is worth noting that in contrast to the development in Denmark, some indicators suggest that the increase in the level of education in the US has flattened out since the mid-1970s (U.S. Census Bureau, 2012), as also noted by Robinson \& Jackson (2001). In other words, differences in the development in education may be a plausible explanation for the divergent trends in trust in the two countries after all. Another plausible explanation is that the cohorts growing up during the Vietnam War and the civil rights movement in the USA had collective experiences early in life affecting trust negatively (Uslaner, 2002), which are unparalleled in Denmark. 


\section{Notes}

${ }^{1}$ According to this definition, social trust is distinct from other forms of trust in that it does not concern perceptions of specific others or specific groups. The latter types of trust are often referred to as particularized trust and group- or identity-based trust, respectively. See the discussions in Freitag \& Bauer (2013), Patulny \& Svendsen (2007), Sønderskov (2008) and Uslaner (2002).

${ }^{2}$ However, with Iceland scoring markedly lower than the other countries.

${ }^{3}$ As an alternative to the cultural explanation explaining intergenerational stability in trust by parental socialization early in life, it should be noted that recent research has shown that the stability may also be the result of genetic transmission of trust from parents to children (Sturgis et al., 2009; Hirashi et al., 2008). However, for the present purposes, the important issue is that both perspectives predict stability in trust.

${ }^{4}$ Note that parts of this figure (and Figure 2 and 3) have also been reported in Dinesen \& Sønderskov (2012b).

${ }^{5}$ Note that the wording of the trust question in the American General Social Survey is marginally different than in the remaining surveys. The wording is "Generally speaking, would you say that most people can be trust or that you cannot be careful in life".

${ }^{6}$ The literature on value change typically also consider age explanations, which emphasize how values develop with age over the life course according to changes in life circumstances and position in society. Generally speaking, all individuals are expected to experience the same value change with age (e.g., the transition from being left-wing during youth to becoming more right-wing with age). Unless a society's age composition changes markedly over time, age explanations are generally not suited for explaining value change at the societal level, as the expectation from this perspective is that values are stable at the aggregate level over time as everyone is expected to go through the same value change over the life course. Similar to most developed countries, the age composition has been relatively stable over the last 30 years in Denmark (Statistics Denmark, 2008), and thus, we can disregard age effects as an explanation for the increase in trust.

${ }^{7}$ Statistics Denmark, account BEF1A.

${ }^{8}$ Note, however, that the reliability and validity of the institutional quality measure have been criticized (Kurtz \& Schrank, 2007) and inter-temporal comparison may therefore be somewhat problematic.

${ }^{9}$ The full 1990-2008 panel dataset (Danish Data Archive 2009) only includes respondents who chose to participate in all three waves. We have merged this dataset with the 1990-1999 dataset (Danish Data Archive 2002) to retain respondents who did not participate in 2008.

10 The robustness of the impact of institutional trust on social trust is assessed in a number of ways: omitting associational involvement from the model, controlling for an alternative measure of involvement, dropping respondents affected by non-response in the household income variable, omitting household income from the model (see notes to Supplementary Table A). The coefficient for institutional trust does not change in these models (not shown).

${ }^{11}$ To avoid losing too many observations in the analysis because of non-response on one of the questions about trust in institutions, we included respondents who responded to at least three of the questions. The index has a Cronbach's alpha between 0.69 and 0.74 in the cross-sectional data and the three waves of the panel.

${ }^{12}$ While our results point to a strong effect of education on social trust, it should be noted that recent research have questioned whether this is a causal relationship or rather that it reflects (is confounded by) various unobserved factors (Oskarsson et al., 2014). 


\section{References}

Barro, Robert \& Lee, Jong-Wha. (2010). A New Data Set of Educational Attainment in the World, 1950-2010. NBER Working Paper No. 15902. Downloaded December 21, 2011 from http://www.barrolee.com/data/BL_v1.2/BL(2010)_MF2599_v1.2.dta.

Bekkers, René. (2012). Trust and Volunteering: Selection or Causation? Evidence from a 4 Year Panel Study. Political Behavior, 34(2), 225-247.

Bjørnskov, Christian. (2006). Determinants of generalized trust: A cross-country comparison. Public Choice, 130(1), 1-21.

Bjørnskov, Christian. (2008). Social Trust and Fractionalization: A Possible Reinterpretation. European Sociological Review, 24(3), 271-283.

Brehm, John \& Rahn, Wendy. (1997). Individual-Level Evidence for the Causes and Consequences of Social Capital. American Journal of Political Science, 41(3), 999-1023.

Clark, April K. \& Eisenstein, Marie A. (2013). Interpersonal Trust: An Age-Period-Cohort Analysis Revisted. Social Science Research, 42(2), 361-375.

Coleman, James S. (1990). Foundations of Social Theory. Cambridge: Harvard University Press.

Danish Data Archive. (1981). Study DDA-228: Politiske værdier i Danmark 1979. Obtained from the Danish Data Archive.

Danish Data Archive. (2002). Study DDA-9991: International værdiundersøgelse (Danmark): Panel 1990-1999”. Obtained from the Danish Data Archive.

Danish Data Archive. (2009). Den danske værdiundersøgelse, panel 1990-2008”. Obtained from the Danish Data Archive.

Danish Data Archive. (2011). Study DDA-24772: Social ulighed i Danmark (ISSP 2009). Obtained from the Danish Data Archive.

Delhey, Jan \& Newton, Kenneth. (2003). Who trusts?: The origins of social trust in seven societies. European Societies, 5(2), 93-137.

Delhey, Jan \& Newton, Kenneth. (2005). Predicting Cross-National Levels of Social Trust: Global Pattern or Nordic Exceptionalism?, European Sociological Review, 21(4), 311-327.

Dinesen, Peter Thisted. (2012a). Parental Transmission of Trust or Perceptions of Institutional Fairness? Generalized Trust of Non-Western Immigrants in a High Trust Society. Comparative Politics, 44(3), 273-289.

Dinesen, Peter Thisted (2012b). Does Generalized (Dis)Trust Travel? Examining the Impact of Cultural Heritage and Destination-Country Environment on Trust of Immigrants. Political Psychology, 33(4), 495-511.

Dinesen, Peter Thisted. (2013). Where You Come From or Where You Live? Examining the Cultural and Institutional Explanation of Generalized Trust Using Migration as a Natural Experiment. European Sociological Review, 29(1), 114-128.

Dinesen, Peter Thisted \& Sønderskov, Kim Mannemar. (2012a). Trust in a time of increasing diversity: On the relationship between ethnic heterogeneity and social trust in Denmark from 1979 until today. Scandinavian Political Studies, 35(4), 273-294. 
Dinesen, Peter Thisted \& Sønderskov, Kim Mannemar. (2012b). Hvorfor stiger tilliden?. Politica, 44(1), 87-110.

Dinesen, Peter Thisted, \& Sønderskov, Kim Mannemar. (2013). Ethnic Diversity and Social Trust: The Role of Exposure in the Micro-Context. Paper presented at Ethnic Diversity and Social Capital, Berlin, May 24-25, 2013.

EVS. (2011). Longitudinal file 1981-2008; Pre-release v.1.0.0 as of April 30, 2011. Downloaded December 9, 2011 from http://dx.doi.org/10.4232/1.4804.

Fairbrother, Malcolm, \& Martin, Isaac W. (2013). Does inequality erode social trust? Results from multilevel models of US states and counties. Social Science Research, 42(2), 347-360.

Finansministeriet. (2010). Indkomstudvikling og -fordeling i Danmark 1983-2007. Downloaded December 21, 2011 from http://www.fm.dk/Nyheder/Pressemeddelelser/2010/03/ /media/Files /Nyheder/Pressemeddelelser/2010/03/Indkomstudvikling\%20og\%20fordeling\%20i\%20danmark\%2 083\%20til\%2007/indkomstudvikling_og_fordeling_i_danmark_83_07.ashx.

Freitag, Markus, \& Bauer, Paul C. (2013). Testing for measurement equivalence in surveys dimensions of social trust across cultural contexts. Public Opinion Quarterly, 77(S1), 24-44.

Gächter, Simon, Benedikt, Herrman \& Thöni, Christian. (2004). Trust, voluntary cooperation, and socio-economic background: survey and experimental evidence. Journal of Economic Behavior and Organization, 55(4), 505-531.

Glanville, Jennifer L., \& Paxton, Pamela. (2007). How do we learn to trust? A confirmatory tetrad analysis of the sources of generalized trust. Social Psychology Quarterly, 70(3), 230-242.

Glenn, Norval D. (2005). Cohort analysis, Second eds. Thousand Oaks: Sage.

GSS (2011) “GSS 2010 merged with all cases and variables (Release 1, Oct. 2011)”, Downloaded December 9, 2011 from http://www3.norc.org/GSS+Website/Download/STATA+v8.0+Format/.

Hirashi, Kai, Yamagata, Shinji, Shikishima, Chizuru \& Ando, Juku. (2008). Maintenance of genetic variation in personality through control of mental mechanisms: a test of trust, extraversion and agreeableness. Evolution and Human Behavior, 29, 79-85.

Kaufmann, Daniel, Kraay, Aart \& Mastruzzi, Massimo. (2011). The Worldwide Governance Indicators (WGI) project. The World Bank. Downloaded December 21, 2011 from http://info.worldbank.org/governance/wgi/index.asp.

Knack, Stephen \& Keefer, Phillip. (1997). Does social capital have an economic payoff? A crosscountry investigation. Quarterly Journal of Economics, 112(4) 1251-1288.

Knack, Stephen. (2002). Social capital and the quality of government: Evidence from the states. American Journal of Political Science, 46(4), 772-785.

Kurtz, Marcus J., \& Schrank, Andrew. (2007). Growth and governance: Models, measures, and mechanisms. Journal of Politics, 69(2), 538-554.

Nannestad, Peter, Svendsen, Gert Tinggard, Dinesen, Peter Thisted, \& Sønderskov, Kim Mannemar. (2014). Do Institutions or Culture Determine the Level of Social Trust? The Natural Experiment of Migration from Non-western to Western Countries. Journal of Ethnic and Migration Studies, 40(4), 544-565. 
Oskarsson, Sven, Dawes, Chris T., Dinesen, Peter Thisted, Johannesson, Magnus, \& Magnusson, Patrik K. E. (2014). Education and Social Trust: Testing a Causal Hypothesis Using the Discordant Twin-Pair Design. Mimeo.

Patulny, Roger V. \& Svendsen, Gunnar Lind Haase (2007) Exploring the social capital grid: bonding, bridging, qualitative, quantitative, International Journal of Sociology and Social Policy, 27(1/2), 32-51.

Putnam, Robert D. (1993). Making Democracy Work: Civic traditions in modern Italy. Princeston: Princeton University Press.

Putnam, Robert D. (1995). Tuning In, Tuning Out: The Strange Disappearance of Social Capital in America. PS. Political Science and Politics, 28(4), 664-683.

Putnam, Robert D. (2000). Bowling alone: The Collapse and Revival of American Community. New York: Simon \& Schuster.

Rice, Tom W. \& Feldman, Jan L. (1997). Civic culture and democracy from Europe to America. Journal of Politics, 59(4), 1143-1172.

Robbins, Blaine G. (2012). Institutional Quality and Generalized Trust: A Nonrecursive Causal Model. Social Indicators Research, 107(2), 235-258.

Robinson, Robert V. \& Jackson, Elton F. (2001). Is Trust in Others Declining in America? An AgePeriod-Cohort Analysis. Social Science Research, 30, 117-145.

Rostila, Mikael. (2007). Social capital and health in European welfare regimes: a multilevel approach. Journal of European Social Policy, 17, 223-239.

Rothstein, Bo \& Stolle, Dietlind. (2008). The State and Social Capital. An Institutional Theory of Generalized trust. Comparative Politics, 40(4), 441-60.

Rothstein, Bo \& Uslaner, Eric. (2005). All for All: Equality, Corruption, and Social Trust. World Politics, 58(1) 41-72.

Rönnerstrand, Björn. (2013). Social capital and immunisation against the 2009 A (H1N1) pandemic in Sweden. Scandinavian Journal of Public Health, 41(8), 853-859.

Scholz, John T. \& Lubell, Mark (1998). Trust and taxpaying: Testing the heuristic approach to collective action. American Journal of Political Science, 42(2), 398-417.

Schwadel, Philip \& Stout, Michael (2012). Age, Period, and Cohort Effects on Social Capital. Social Forces, 91, 233-252.

Sears, David O. \& Levy, Sheri. (2003). Childhood and Adult Political Development, pp. 60-109 in Sears, David, Huddy, Leonie, Jervis, Robert (eds.). Oxford Handbook of Political Psychology. New York: Oxford University Press.

Statistics Denmark (2008). 60 år i tal - Danmark siden 2. verdenskrig. Copenhagen: Statistics Denmark.

Stolle, Dietlind. (2001). Clubs and Congregations: The Benefits of Joining an Association, pp. 202244 in Karen Cook (ed.). Trust in society. New York: Russell Sage Foundation.

Sturgis, Patric, Read, Sanna, Hatemi, Peter K., Zhu, Gu, Trull, Tim, Wright, Margaret J. \& Martin, Nicholas. (2009). A Genetic Basis for Social Trust?. Political Behavior, 32(2), 205-230. 
Sønderskov, Kim Mannemar (2008). Making cooperation work: Generalized social trust and large$N$ collective action. Aarhus: Politica.

Sønderskov, Kim Mannemar. (2011a). Explaining Large-N Cooperation: Generalized Social Trust and the Social Exchange Heuristic. Rationality and Society, 23(1), 51-74.

Sønderskov, Kim Mannemar. (2011b). Does Generalized Social Trust Lead to Associational Membership? Unravelling a Bowl of Well-Tossed Spaghetti. European Sociological Review, 27(4), 419-434.

Tabellini, Guido (2008). Presidential Address. Institutions and Culture. Journal of the European Economic Association, 6(2-3), 255-294.

US Census Bureau (2012). Educational Attainment in the United States: 2009. U.S. Census Bureau. Uslaner, Eric. (2002). The Moral Foundation of Trust. New York: Cambridge University Press.

Uslaner, Eric. (2008). Where You Stand Depends On Where Your Grandparents Sat: The Inheritability of Generalized Trust. Public Opinion Quarterly, 72(4), 725-740.

Wang, Lanlan \& Gordon, Peter. (2011). Trust and institutions: A multilevel analysis. Journal of Socio-Economics, 40(5), 583-593.

WVS (2009). WVS official 5 wave aggregate 1981-2008 v.20090914. Downloaded September 15, 2011 from http://www.wvsevsdb.com/wvs/WVSData.jsp. 


\begin{tabular}{|c|c|c|c|c|c|}
\hline \multirow[t]{2}{*}{ Variable } & \multirow[t]{2}{*}{ Coding } & \multicolumn{4}{|c|}{ Mean/Std.dev or distribution } \\
\hline & & Cross section data & Panel - wave 1 & Panel - wave 2 & Panel - wave 3 \\
\hline Social trust & $\begin{array}{l}\text { "Generally speaking, do you think that most people can be } \\
\text { trusted or that you cannot be too careful in dealing with } \\
\text { other people?" with two response categories: "Most people } \\
\text { can be trusted" or "You cannot be too careful" }\end{array}$ & $\begin{array}{l}\text { "Most people can be } \\
\text { trusted": } 76 \%\end{array}$ & $\begin{array}{l}\text { "Most people can be } \\
\text { trusted": } 71 \%\end{array}$ & $\begin{array}{l}\text { "Most people can be } \\
\text { trusted": } 74 \%\end{array}$ & $\begin{array}{l}\text { "Most people can be } \\
\text { trusted": } 81 \%\end{array}$ \\
\hline Birth cohort & $\begin{array}{l}\text { Decade of birth (pre } 1930-1980 \text { 's); } \\
\text { respondents born before } 1930 \text { are collapsed in a single } \\
\text { category }\end{array}$ & $\begin{array}{l}\text { Pre 1930: } 4 \%, 30 \text { 's: } 10 \%, \\
40 \text { s: } 19 \%, 50 \text { s: } 19 \% \\
\text { 60's: } 21 \%, 70 \text { 's: } 15 \% \\
80 \text { 's: } 12 \%\end{array}$ & $\begin{array}{r}\text { Pre 1930: } 5 \\
60\end{array}$ & $\begin{array}{l}\%, 30 \text { 's: } 13 \%, 40 \text { s: } 22 \% \\
\text { s: } 28 \%, 70 \text { 's: } 5 \%, 80 \text { 's: }\end{array}$ & 50's: $28 \%$ \\
\hline Education & $\begin{array}{l}\text { Five categories: 1) primary school, 2) vocational education, } \\
\text { 3) shorter post-secondary education (1-2 years post high } \\
\text { school), 4) medium-long post-secondary education ( } 3-4 \\
\text { years post high school), and 5) academic education (more } \\
\text { than } 4 \text { years post high school) }\end{array}$ & $\begin{array}{c}\text { 1: } 22 \%, 2: 30 \% \\
3: 21 \%, 4: 17 \%, 5: 10 \%\end{array}$ & $\begin{array}{l}1: 23 \%, 2: 35 \%, 3: \\
23 \%, 4: 13 \%, 5: 7 \%\end{array}$ & $\begin{array}{l}\text { 1: } 21 \%, 2: 36 \%, 3: \\
20 \%, 4: 14 \%, 5: 9 \%\end{array}$ & $\begin{array}{l}1: 20 \%, 2: 31 \%, 3: \\
26 \%, 4: 15 \%, 5: 9 \%\end{array}$ \\
\hline $\begin{array}{l}\text { Institutional } \\
\text { trust }\end{array}$ & $\begin{array}{l}\text { Index with range } 0-1 \text { based on items on trust in the } \\
\text { parliament, the judiciary, the police, and the public sector }\end{array}$ & $0.63 / 0.14$ & $0.60 / 0.16$ & $0.59 / 0.15$ & $0.65 / 0.15$ \\
\hline Gender (female) & Dummy variable where 1 indicates female & Female: $50 \%$ & & Female: $49 \%$ & \\
\hline $\begin{array}{l}\text { Place of birth } \\
\text { (native) }\end{array}$ & $\begin{array}{l}\text { Dummy variable where } 1 \text { indicates native (as opposed to } \\
\text { foreign born) }\end{array}$ & Native: $94 \%$ & & Native: $97 \%$ & \\
\hline $\begin{array}{l}\text { Household } \\
\text { income }\end{array}$ & $\begin{array}{l}\text { Three categories indicating the relative level of household } \\
\text { income compared to the other respondents in the survey } \\
\text { (below the } 25 . \text { percentile, within the interquartile range, or } \\
\text { above the } 75 . \text { percentile) and the fourth category being non- } \\
\text { response }^{\mathrm{a}}\end{array}$ & $\begin{array}{l}\text { 1: } 19 \%, 2: 41 \% \\
3: 14 \%, 4: 26 \%\end{array}$ & $\begin{array}{l}\text { 1: } 17 \%, 2: 46 \%, 3: \\
25 \%, 4: 11 \%\end{array}$ & $\begin{array}{c}1: 24 \%, 2: 44 \%, 3: \\
\quad 27 \%, 4: 5 \%\end{array}$ & $\begin{array}{l}\text { 1: } 21 \%, 2: 39 \%, 3: \\
22 \%, 4: 19 \%\end{array}$ \\
\hline $\begin{array}{l}\text { Associational } \\
\text { involvement }\end{array}$ & $\begin{array}{l}\text { Dummy variable where } 1 \text { indicates that the respondent did } \\
\text { voluntary work in at least one of } 15 \\
\text { organizations/associations at the time of the survey }^{\text {b }}\end{array}$ & Involved: $34 \%$ & Involved: $37 \%$ & Involved: $52 \%$ & Involved: 43\% \\
\hline Life satisfaction & "How satisfied or dissatisfied are you with life nowadays?" & $0.82 / 0.20$ & $0.83 / 0.18$ & $0.83 / 0.15$ & $0.84 / 0.18$ \\
\hline
\end{tabular}


10 response categories from zero ("Very dissatisfied") to 1

\section{("Very satisfied")}

"How much influence do you have over your own life?" 10

Self-efficacy

response categories from zero ("No influence at all") to 1 ("A

lot of influence")

Notes: The descriptives for the cross-sectional data is based on the 1,455 respondents included in Models I-III. The descriptives for the panel data is based on the 324 respondents included in Model

IV. ${ }^{a}$ : Non-response (including those not wishing to answer the question) was included as a category to avoid excluding a number of respondents from the analysis. As non-response may be affected by trust (and hence the risk of simultaneity bias), we also estimated models omitting the non-response categories. ${ }^{b}:$ We opted for this operationalization as voluntary work more likely involves interaction with other people than mere membership (which may be passive) and hence comes closer to the main mechanism linking participation in organizations to trust (Sønderskov, 2011b). As an alternative measure, we tried using a summated scale of the number of voluntary associations in which the respondent carried out voluntary work. 